\title{
Effectiveness of Some Educational Methods and Tools on Improving the Level of Understanding of Biostatistics among Medical Students and Paramedical Postgraduate Students
}

\author{
Nezhat Shakeri ${ }^{1}$ \\ ${ }^{1}$ Department of Biostatistics, Faculty of Paramedical Sciences, Shahid Beheshti University of Medical Sciences, \\ Tehran, Iran \\ Correspondence: Nezhat Shakeri, Department of Biostatistics, Faculty of Paramedical Sciences, Darband St., \\ Tajrish, Tehran 1971653313, Iran. Fax: 98-212-270-7347. E-mail: n.shakeri@sbmu.ac.ir
}

Received: October 14, 2015 Accepted: March 25, 2016 Online Published: April 13, 2016

doi:10.5539/gjhs.v8n11p302 URL: http://dx.doi.org/10.5539/gjhs.v8n11p302

\begin{abstract}
It has been observed that medical students and researchers lack sufficient knowledge in understanding statistical concepts. This indicates the importance of improving the level of instruction in this field. This experimental study was conducted to introduce and investigate the effectiveness of some educational methods and tools in improving the level of understanding of biostatistics among medical students and paramedical postgraduate students. For this purpose, from 40 medical students and 20 paramedical postgraduate students, who attended the biostatistics course, pre-test and post-test questionnaires were collected. The medical students were divided into two training groups, namely, training with the help of software (intervention group), and the traditional (lecture method) group. The paramedical postgraduate students were also divided into two groups, except that for the intervention group, in addition to training with the help of software, educational DVDs were also provided. Knowledge, attitude and the awareness index of the students were determined by using a questionnaire. Post-test results indicate that, the awareness index in the intervention group was significantly higher than the control group $(\mathrm{P}<0.05)$. The new method of teaching significantly upgraded the knowledge of the students $(\mathrm{P}<0.05)$ and increased the level of attitude of the medical students $(\mathrm{P}<0.04)$. Comparing the post-test results of the two groups, i.e., medical students and paramedical postgraduate students, demonstrated that a combination of software and instructional DVDs had a positive effect on the desired outcome $(\mathrm{P}<0.01)$. Usage of statistical software and additional virtual methods will contribute to increasing the level of knowledge and attitude of the students toward biostatistics. The training method and, accordingly, the curricula of biostatistics courses in medical and paramedical schools must be revised.
\end{abstract}

Keywords: educational technology, statistical software, training method

\section{Introduction}

With the scientific and policy perspectives of the future, a growing need of medical students and researchers in biostatistics is undeniable. According to some studies, many published medical research articles contain statistical errors (Strasak et al., 2007). The teaching of biostatistics and the problems of medical students in understanding statistical concepts is a topic presented in many sources (Akinsola et al., 2014; Altman \& Bland, 1991; Polychronopoulou et al., 2011; Windish, 2011). The negative attitude of students towards statistics has been repeatedly reported (Martin, 2003; Ograjenšek \& Bavdaž Kveder, 2003; Ograjenšek, 2005), and a review of the literature indicates that the level of understanding of medical students and practitioners of biostatistics is very low (Maha \& Tantawi, 2009). Gore et al. believe that it is essential for medical professionals to upgrade their biostatistics knowledge frequently in order to improve research quality (Gore et al., 2012).

Studies show that only 21 percent of physicians correctly understand the interpretation of data in articles (Ghajarzadeh, Abdollahzadeh, \& Rafiei, 2011; Windish, Huot, \& Green, 2007). These studies show that although medical statistics is taught at all levels of education, its effectiveness is questionable. In the study, conducted in the United States of America, 277 medical residents (75.5\%) acknowledged that they did not understand $75 \%$ of the concepts of biostatistics in articles, while $95 \%$ of them felt that it was important to understand these concepts. This means that most of the residents in this research had a deficient knowledge in the field of 
biostatistics and needed help in interpreting the results published in medical journals. As a result, resident training programs should include teaching statistics more effectively in order to prepare students for important long-term learning skills (Wulff et al., 1987).

In a research conducted in the field of dentistry in the United States, with the aim of assessing the understanding of statistics, the results show that the residents of maxillofacial surgery have little knowledge of statistics. Therefore, curricula of residency courses should include a higher level of statistical education (Best \& Laskin, 2013). In a study aimed at evaluating the cognition, comprehension and application of biostatistics in research among postgraduate students in periodontics in India, Swetha et al. found that $80 \%$ of students were aware of the importance of biostatistics in research, while only $3.0 \%$ were able to perform statistical analysis independently. They concluded that the level of understanding and application is low, and further attention in this regard is required (Swetha et al., 2014). According to the Daher and Amin (2010) study, which was conducted to explore medical students' attitude toward biostatistics, the students understood the relevance of the subject to real health issues, but a majority of the students (78.1\%) agreed that a lack of practicing exercises was the cause of declining interest in the subject, while $84.6 \%$ recommended practical sessions for designing research and data collection (Daher \& Amin, 2010).

In order to find reasons for the lack of knowledge of statistics of medical practitioners, Stander conducted a study which addresses the time allotted to the course, its content, teachers' methods and the quality of their lectures. It concludes that in order to motivate medical students to learn statistics, substantial change in the method of teaching is required (Stander, 1999). In a survey by West and Ficalora (2007), it is shown that only $17.6 \%$ of medical students, internal medicine residents, and internal medicine teaching faculties believe that they have acceptable training in biostatistics, and only $14.6 \%$ feel prepared to conduct a statistical analysis (West \& Ficalora, 2007). In teaching statistics there are some references which suggest that incorporation of various techniques to actively involve the students in the learning process, such as working through some examples, discussing practical issues, etc. are effective (Gelman, 2005). Research has shown that educational technology is an effective factor in teaching statistics (Chance et al., 2007). Therefore, the selection of an appropriate instructional method, or a combination of several different methods, can lead to increased training efficiency.

In this study an attempt has been made to introduce educational methods for teaching biostatistics and investigate their effectiveness in the knowledge and attitude of medical science students. Since biostatistics is one of the subjects of medical and paramedical postgraduate courses, in this study both groups were considered for further investigation.

\section{Methods}

This experimental study was carried out at Shahid Beheshti University of Medical Sciences in Iran.

\subsection{Participants' Characteristics}

From among classrooms of biostatistics of medical students and postgraduate paramedical students (P.G.) some classrooms were randomly selected as clusters, all the students of each classes were eligible to participate in the study. If someone didn't wish to participate, s/he was excluded from the study. Postgraduate paramedical students were from different streams, like nursing, lab. Sciences, physiology and so on.

\subsection{Sampling Procedure}

\subsubsection{Research Design}

In the medical group, clusters were randomly divided into two groups: A classroom as intervention group, in which the method of training was with the help of software, and some other classrooms as control group, in which the common traditional method, i.e., the lecture method was used. In the postgraduate group, classrooms were also divided into two groups, with the difference that the intervention group was not only trained with the help of software, but was also provided with instructional DVDs, so that whenever they felt the need they would be able to hear and see the description of the teacher.

\subsubsection{Measures and Covariates}

In order to collect data, a standard questionnaire previously used for medical students was used (Ghajarzadeh et al., 2011). With regard to the validity and reliability of the questionnaire, the same paper was cited. The questionnaire consisted of 8 questions on the Likert scale (from 1: absolutely disagree to 5: absolutely agree) that was used to determine the extent of the knowledge and attitude of students toward biostatistics. Questions 1, 3, 4, 5 measure the attitude of the students (Attitude index on the scale 4-20), and the remaining questions were used to measure their knowledge (Knowledge index on the scale 4-20). The awareness index was defined using all the 
8 questions contained in the questionnaire, on the scale 8-40. Considering that the third question is in the opposite direction, it should be calculated in reverse. In order to assess the effectiveness of the intervention on the students' knowledge and attitude, the questionnaire was administered to the students, once at the beginning and again at the end of the semester. If the students of the traditional class and intervention class had no significant differences with each other at the beginning of the semester, after intervention, results of the two groups were compared by using the Mann-Whitney test. However, if at the baseline there were significant differences between the groups, adjustment has been made by eliminating the effect of the baseline.

\subsubsection{Sample Size Determination}

To determine the sample size, a pilot study was carried out. The standard deviation of the awareness index was found to be 4 , considering $\alpha=0.05, \beta=0.2, d=4.3$ the minimum sample size of 11 was found for each group.

\subsubsection{Interventions}

For medical students, intervention would be on the basis of teaching biostatistics via lecture and software simultaneously. In this method, in addition to learning the theory of biostatistics, students have to employ statistical software to solve the exercises. The control group was taught by the traditional method, i.e., lecture. In the case of paramedical postgraduate students, in order to intervene, in addition to the statistical software, instructional DVDs were also provided. The reason for providing instructional DVDs was that according to the author's experience, it was observed that postgraduate students needed more explanation about the topic, therefore the DVDs could help the students to review the subject repeatedly.

Considering that in the traditional method the students must solve statistical exercises manually, at most using a calculator, it is not possible for an instructor to cover complicated formulae and methods. However, in the new method students can perform data analysis by using statistical software without wasting time or facing great difficulty. On that basis, Table 1 shows the curricula that were used in the two methods - the traditional and the new method, comparatively.

Table 1. Comparative curricula of biostatistics at the medical and paramedical postgraduate level

\begin{tabular}{|c|c|}
\hline Traditional method & New method \\
\hline Definitions and Terms & Definitions and Terms \\
\hline Ways of data collection. & Ways of data collection. \\
\hline \multirow[t]{2}{*}{ Types of variables } & Types of variables \\
\hline & Computerization of data \\
\hline $\begin{array}{l}\text { Descriptive statistics with a small samples as examples, } \\
\text { using a calculator }\end{array}$ & $\begin{array}{l}\text { Descriptive statistics of data by using computer without } \\
\text { any limitation in sample size }\end{array}$ \\
\hline Central Tendency (Mean, Median, Mode) & Central Tendency (Mean, Median, Mode) \\
\hline Quartiles & Quartiles, Percentiles \\
\hline Measures of Dispersion & Measures of Dispersion \\
\hline $\begin{array}{l}\text { Histogram, Bar diagram, Pie diagram, Error bar, Polygon, } \\
\text { Cumulative polygon }\end{array}$ & $\begin{array}{l}\text { Histogram, Bar diagram, Pie diagram, Error bar, Box plot } \\
\text { (with outliers), Polygon, Cumulative Polygon, Scatter } \\
\text { diagram, Normal Curve. }\end{array}$ \\
\hline $\mathrm{Z}$ - tests & $\mathrm{Z}-$ tests \\
\hline $\mathrm{t}$ - tests & $\mathrm{t}-$ tests \\
\hline \multirow[t]{2}{*}{ P-value } & P-value \\
\hline & Relevant Non-parametric tests \\
\hline \multirow[t]{4}{*}{ One Way Analysis of Variance } & One-way analysis of variance \\
\hline & Relevant non-parametric tests \\
\hline & Two-way analysis of variance \\
\hline & Analysis of covariance \\
\hline \multirow[t]{2}{*}{ Chi - Square } & Chi-square \\
\hline & Fisher exact test \\
\hline
\end{tabular}


The local ethical registration number of the study is 131-91/12/6. Students were assured of the confidentiality of their answers. Written consent was obtained from all participants. Data analyses were done by SPSS (16).

\section{Results}

\subsection{Recruitment}

At the beginning of the semester, 2011-2012, 140 medical students and 52 paramedical postgraduate students were recruited to the study.

\subsection{Baseline Data}

Table 2 shows the details of the demographic profile of the samples.

Table 2. Percentage or mean (SD) of the demographic characteristics of the samples-Shahid Beheshti University of Medical Sciences, 2012

\begin{tabular}{lll}
\hline & Medical Students & Paramedical Postgraduate Students \\
\hline Sex (\%Boys) & 46 & $\mathbf{2 5}$ \\
Age (Year) (Mean(SD)) & $21(1)$ & $\mathbf{2 6 ( 5 )}$ \\
Previous familiarity with statistics (\%) & 6 & $\mathbf{7 6}$ \\
\hline
\end{tabular}

\subsection{Statistics and Data Analysis}

As it is shown in Table 2, the mean of the age of medical students and P.G.s are 21 and 26, respectively; meaning that medical students are younger than P.G.s. On the other hand, a very low percentage of medical students had previous familiarity with statistics compared to the postgraduate group (6\% vs. $76 \%)$. Due to these differences, data analyses were performed separately.

Table 3 represents the mean (SD) of variables, before and after intervention, among medical students with respect to the teaching method, i.e., the new and traditional methods. The results show that the traditional approach has been able to upgrade the averages related to the questions 6,7 and 8 significantly. The averages in rows 1, 2, 6, 7 and 8 have been dramatically increased in the new method $(\mathrm{P}<0.05)$.

In the traditional method, question 5 "As an intelligent reader of medical references, it is required to know statistics to some extent", shows that the estimated mean has dropped from 4.1 to 3.2, before and after intervention, respectively $(\mathrm{P}<0.013)$. The mean of the knowledge of the medical students in the new method changed from 8.2 in pre-test to 12.2 in post-test $(\mathrm{P}<0.0005)$, while in the traditional method it changed from 9.4 to $11.7(\mathrm{P}<0.005)$. The difference between the means of the knowledge index of the two groups at the end of the semester was found to be significant $(12.2$ vs. 11.7) $(\mathrm{P}<0.03)$. The post-test mean of the attitude index of the medical students significantly increased in intervention group compared to the control group $(14.4 \pm 3.4 \mathrm{vs}$. $12.3 \pm 3.7)(\mathrm{P}<0.04)$. It is noticeable that the attitude of the students in the traditional method decreased significantly, from 14.1 at the beginning of the semester to 12.3 at the end $(\mathrm{P}<0.05)$. The average of the awareness index among medical students in the new method, before starting the semester, was found to be 21.9, and at the end of the semester it was found to be 26.6 , which are significantly different $(\mathrm{P}<0.0005)$, indicating the effectiveness of the new method. However, no significant differences were observed between before and after the traditional method in this score, 23.6 and 23.8, respectively. The post-test awareness index in the intervention and control groups, was significantly different ( $26.6 \pm 5.7$ vs. $23.8 \pm 5.9, \mathrm{P}<0.02)$. 
Table 3. The mean (SD) of the questions responded to by medical students according to the method of training before and after intervention-Shahid Beheshti University of Medical Sciences, 2012

\begin{tabular}{|c|c|c|c|c|c|}
\hline \multirow{2}{*}{\multicolumn{2}{|c|}{ Question }} & & \multirow{2}{*}{$\begin{array}{l}\text { New } \\
\text { Method } \\
\text { Mean (SD) }\end{array}$} & \multirow{2}{*}{$\begin{array}{l}\text { Traditional } \\
\text { Method } \\
\text { Mean (SD) }\end{array}$} & \multirow[t]{2}{*}{ Sig } \\
\hline & & & & & \\
\hline \multirow[t]{3}{*}{1} & \multirow[t]{2}{*}{ I (as a medical student) like to learn more statistics. } & Pre-test & $3.0(1.1)$ & $3.1(1.1)$ & 0.4 \\
\hline & & Post-test & $3.4(1.3)$ & $2.8(1.4)$ & 0.1 \\
\hline & Sig & & 0.05 & 0.2 & \\
\hline \multirow[t]{3}{*}{2} & \multirow[t]{2}{*}{ I understand almost all the statistical phrases in the journals. } & Pre-test & 2.6(0.9) & 2.6(0.9) & 0.5 \\
\hline & & Post-test & $2.9(0.8)$ & $2.7(0.9)$ & 0.4 \\
\hline & Sig & & 0.05 & 0.8 & \\
\hline \multirow[t]{3}{*}{3} & \multirow{2}{*}{$\begin{array}{l}\text { In medical research, I think knowledge of statistics is not } \\
\text { required. }\end{array}$} & Pre-test & $1.9(1.1)$ & $2.0(1.1)$ & 0.7 \\
\hline & & Post-test & $2.0(1.2)$ & $2.4(1.3)$ & 0.3 \\
\hline & Sig & & 0.8 & 0.2 & \\
\hline \multirow[t]{3}{*}{4} & \multirow[t]{2}{*}{ I generally feel I have to use statistics to reach a medical decision. } & Pre-test & $2.8(1.0)$ & $2.9(1.0)$ & 0.4 \\
\hline & & Post-test & $3.0(1.1)$ & $2.6(1.0)$ & 0.2 \\
\hline & Sig & & 0.3 & 0.2 & \\
\hline \multirow[t]{3}{*}{5} & \multirow{2}{*}{$\begin{array}{l}\text { As an intelligent reader of medical references, it is required to } \\
\text { know statistics to some extent. }\end{array}$} & Pre-test & $3.8(1.0)$ & $4.1(1.0)$ & 0.09 \\
\hline & & Post-test & $4.0(1.0)$ & $3.2(1.3)$ & 0.03 \\
\hline & Sig & & 0.4 & 0.013 & \\
\hline \multirow[t]{3}{*}{6} & \multirow{2}{*}{$\begin{array}{l}\text { I understand the interpretation of } p \text {-value as mentioned in medical } \\
\text { studies. }\end{array}$} & Pre-test & $1.4(0.7)$ & $1.8(1.1)$ & 0.01 \\
\hline & & Post-test & $2.8(1.2)$ & $3.0(1.2)$ & 0.6 \\
\hline & Sig & & 0.0005 & 0.0005 & \\
\hline \multirow[t]{3}{*}{7} & \multirow[t]{2}{*}{ I can interpret the statistical results of medical studies. } & Pre-test & $2.2(1.0)$ & $2.6(1.0)$ & 0.03 \\
\hline & & Post-test & $3.4(0.8)$ & $3.3(0.9)$ & 0.04 \\
\hline & Sig & & 0.0005 & 0.01 & \\
\hline \multirow[t]{12}{*}{8} & \multirow{2}{*}{$\begin{array}{l}\text { I can suggest an appropriate statistical method in order to answer } \\
\text { the research questions. }\end{array}$} & Pre-test & $2.1(1.0)$ & $2.4(0.9)$ & 0.04 \\
\hline & & Post-test & $3.2(1.1)$ & $2.9(1.0)$ & 0.04 \\
\hline & Sig & & 0.0005 & 0.03 & \\
\hline & \multirow[t]{2}{*}{ Knowledge Index } & Pre-test & $8.2(2.7)$ & $9.4(2.9)$ & 0.02 \\
\hline & & Post-test & $12.2(3.0)$ & $11.7(3.0)$ & 0.03 \\
\hline & Sig & & 0.0005 & 0.005 & \\
\hline & \multirow[t]{2}{*}{ Attitude Index } & Pre-test & $13.6(3.0)$ & $14.1(2.9)$ & 0.5 \\
\hline & & Post-test & $14.4(3.4)$ & $12.3(3.7)$ & 0.04 \\
\hline & Sig & & 0.1 & 0.05 & \\
\hline & \multirow[t]{2}{*}{ Awareness Index } & Pre-test & $21.9(4.3)$ & $23.6(4.4)$ & 0.03 \\
\hline & & Post-test & $26.6(5.7)$ & $23.8(5.9)$ & 0.02 \\
\hline & Sig & & 0.0005 & 0.8 & \\
\hline
\end{tabular}

Table 4 shows the mean (SD) of the questions to which the paramedical postgraduate students responded, according to the method of training before and after intervention. The impact of the traditional training, before and after intervention, is related only to items 6 and 7. The effect of the use of software and DVDs, related to rows $2,6,7,8$, is significant. Mean $\pm \mathrm{SD}$ of the knowledge of the students in the new method changed from $6.1 \pm 2.6$ at the beginning of the semester to $13.9 \pm 3.3$ at the end $(\mathrm{P}<0.0005)$, while in the traditional method it 
changed from $7.8 \pm 2.6$ to $11.0 \pm 3.5(\mathrm{P}<0.005)$. The post-test mean of the knowledge of the P.G., was significantly higher in the intervention group compared to the control group (13.9 \pm 3.3 vs. $11.0 \pm 3.5)(\mathrm{P}<0.006)$. The mean $\pm \mathrm{SD}$ of the attitude of the students in the new method changed from $15.9 \pm 2.2$ to $16.2 \pm 2.6$, without significant differences; similarly, in the traditional method it was found to be $15.6 \pm 2.6$ before and $15.6 \pm 2.9$ after intervention. The post-test results of the attitude index indicate that there were no significant differences in the intervention group compared to the control group (16.2 \pm 2.6 vs. 15.6 \pm 2.9$)$. The mean $\pm \mathrm{SD}$ of the awareness indicator among the P.G. in the new method, before starting the semester, was found to be 22.1 \pm 4.0 , and at the end of the semester it was found to be $30.3 \pm 4.8$, which are significantly different $(\mathrm{P}<0.0005)$, indicating the effectiveness of the new method. The mean of the awareness index did not show any significant differences before and after intervention in the traditional group (23.4 \pm 4.3 vs. $26.6 \pm 3.6)$. The post-test mean of the index shows significant differences between the intervention group and the control group (30.3 \pm 4.8 vs. 26.6 \pm 3.6$)$ $(\mathrm{P}<0.05)$.

Table 4. The mean (SD) of the questions to which the postgraduate students responded according to the method of training before and after intervention - Shahid Beheshti University of Medical Sciences, 2012

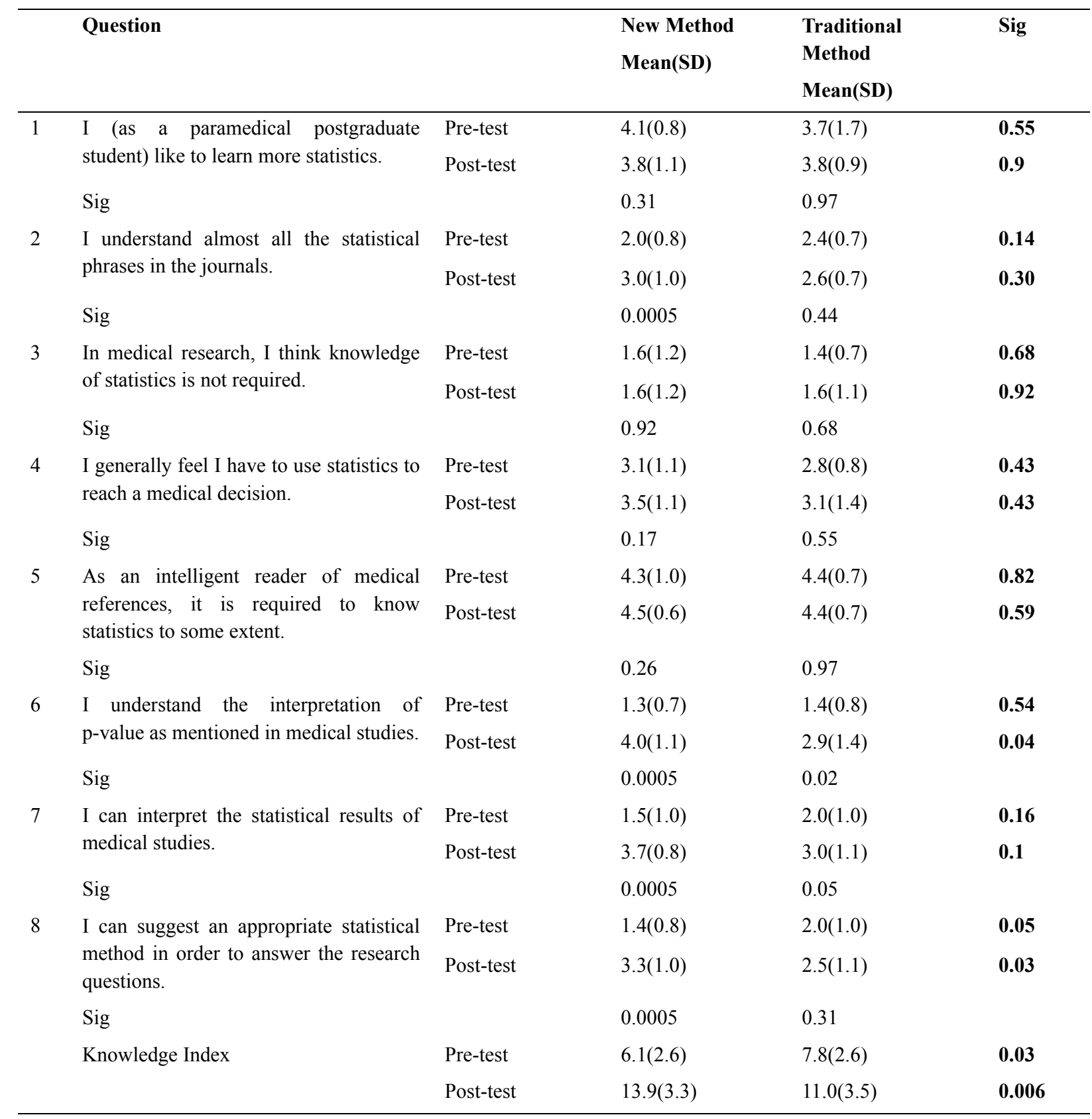




$\begin{array}{lllll}\text { Sig } & & 0.0005 & 0.05 & \\ \text { Attitude Index } & \text { Pre-test } & 15.9(2.2) & 15.6(2.6) & \mathbf{0 . 8} \\ & \text { Post-test } & 16.2(2.6) & 15.6(2.9) & \mathbf{0 . 5} \\ \text { Sig } & & 0.5 & 0.9 & \\ \text { Awareness Index } & \text { Pre-test } & 22.1(4.0) & 23.4(4.3) & \mathbf{0 . 5 7} \\ & \text { Post-test } & 30.3(4.8) & 26.6(3.6) & \mathbf{0 . 0 5} \\ \text { Sig } & & 0.0005 & 0.13 & \end{array}$

The mean of the knowledge index before intervention among medical students varied from 8 to 9 (out of 20), and after intervention it increased to 11-12. This was in range 6 to 8 in the postgraduate group before intervention, and increased to range 11 to 14 after intervention. The mean of the attitude index among medical students was in range 12-14 (out of 20) before and after intervention, while among postgraduates it was in range $15-16$.

Analysis with respect to sex showed that there are no statistically significant differences between males and females, either in the medical or the P.G. group.

\subsection{Participant Flow}

A total number of 140 medical students (half of them in the intervention group) and 52 paramedical postgraduate students (41 of them in the intervention group) were recruited to the study in the primary phase of analysis. The response rate was $95 \%$. Since completing the course was compulsory for the students, all of the participants completed the study. The final measurement was planned to be done at the last session of the semester, while some of the students, due to preparation for final exams, couldn't attend the last session and inevitably didn't respond to the questionnaire. At the end, 40 medical students and 20 postgraduates showed up for the final measurement. It is assumed that attrition was at random.

\section{Discussion}

A comparison of the two groups shows that the new methods effectively enhanced the awareness index of the students. The new method of teaching significantly upgraded the knowledge of the students in both groups. This finding complies with Sami (2010), who believes that medical students' understanding of biostatistics is deficient, while this can easily be changed by using interactive teaching techniques (Sami, 2010). In addition, it complies with Chance, who has shown that educational technology is an effective factor in teaching statistics (Chance et al., 2007).

The results of the study totally comply with the findings of other studies that show that medical students' and physicians' understanding of biostatistics is very low (Akinsola et al., 2014; Ghajarzadeh et al., 2011; Maha \& Tantawi, 2009, West \& Ficalora, 2007). This is unlike the findings, which stated that the level of knowledge of postgraduate medical students was moderate (Wadhwa, Kalyan, \& Kalantharakath, 2015; Gore et al., 2012). It can be concluded situations are not same in every universities.

The attitude of postgraduates toward biostatistics at the beginning of the study was found to be positive; this finding conforms to Wadhwa et al., 2015 and Gore et al., 2012, in which it is stated that the attitude of postgraduate medical students was highly positive (Wadhwa et al., 2015; Gore et al., 2012). The positive attitude of postgraduates can be attributed to their previous familiarity with biostatistics, as well as the fact that the postgraduates were currently involved in research for their thesis.

Although the traditional method has been able to upgrade the level of knowledge of the medical students to some extent, it significantly made their attitude less positive. On the contrary, a significant incremental change of attitude of medical students toward biostatistics has been observed in the new method. As it is seen in Question 5, in the traditional method, "As an intelligent reader of medical references, it is required to know statistics to some extent," the average dropped from 4.1 to 3.2 , before and after intervention, These findings comply with Clayden (1990), who believes theoretical courses risk losing contact with medical students, who come to medical school to become doctors, not statisticians. In some references, dry and tedious mathematical calculations are mentioned as problematic reasons (Freeman et al., 2008).

Similar to the results of Gore et al. (2012) and Khan and Mumtaz (2009), sex was not identified as a factor in the knowledge or attitude of the students (Gore et al., 2012; Khan \& Mumtaz, 2009). 
Comparing the two intervention groups, namely, medical and paramedical postgraduate students, in terms of the awareness index before and after intervention, (which changed from 21.9 to 26.6 in the medical group, and from 22.1 to 30.3 in postgraduates), can be indicative of the usefulness of instructional DVDs.

The biostatistics curricula for medical and paramedical postgraduate groups contain descriptive and analytical statistics. In the traditional method, the instructor is faced with many difficulties while employing complicated mathematical formulae. In the new method, however, using statistical software helps the instructor and students to solve exercises precisely and in a timely manner, and greater attention is given to the interpretation of results. Consequently, the introduced techniques help medical sciences students to enhance their knowledge and attitude, and their ability to interpret and understand the contents of statistics. It is recommended that the curricula of biostatistics in medical schools be designed based on the application of a computer and software.

For further studies, it is suggested that obstacles to the implementation of the proposed method be investigated. The traditional method relies only on the teacher, while a computer-designed education needs a high degree of collaboration between the staff of the computer section, technical section, and the trainer.

The limitation of this study is that the lecturers of the traditional method were two faculty members of biostatistics. It was assumed that there were no significant differences between their teaching methods.

\section{Acknowledgments}

The author thanks Dr. (Ms.) Navideh Nasiri Oskooi and Dr. Alireza Abadi for their cooperation and permission to collect data from their classes. This study was undertaken by a grant of the Department of Research, Shahid Beheshti University of Medical Sciences, Tehran, Iran.

\section{Conflict of Interest}

The authors declare that there is no conflict of interests regarding the publication of this paper.

\section{References}

Akinsola, O. J., James, O., Ibikunle, A. A., \& Adeyemo, W. L. (2014). Understanding biostatistics: A study of Nigerian dental resident doctors. Niger $J$ Exp Clin Biosci, 2, 100-4. http://dx.doi.org/10.4103/2348-0149.144845

Altman, D. G., \& Bland, M. (1991). Improving Doctors Understanding of Biostatistics. Journal of the Royal Statistical Society Series A- Statistics in Society, 154, 223-267. http://dx.doi.org/10.2307/2983040

Best, A. M., \& Laskin, D. M. (2013). Oral and Maxillofacial Surgery Residents Have Poor Understanding of Biostatistics. J Oral Maxillofac Surg., 71(1), 227-34. http://dx.doi.org/10.1016/j.joms.2012.03.010

Clayden, A. D. (1990). Who should teach medical statistics, when, how and where should it be taught? Statistics in Medicine, 9, 1032-1041. http://dx.doi.org/10.1002/sim.4780090906

Chance, B., Ben-Zvi, D., Garfield, J., \& Medina, E. (2007). The Role of Technology in Improving Student Learning of Statistics. Technology Innovations in Statistics Education, 1(1). Retrieved from http://escholarship/org/uc/item/8sd2t4rr/

Daher, A. M., \& Amin, F. (2010). Assessing the perceptions of a biostatistics and epidemiology module: Views of Year 2 medical students from a Malaysian university. A cross-sectional survey. BMC Medical Education, 10, 34. http://dx.doi.org/10.1186/1472-6920-10-34

Freeman, J. V., Collier, S., Staniforth, D., \& Smith, K. J., (2008). Innovations in Curriculum Design: A multi-disciplinary approach to teaching statistics to undergraduate medical students. BMC Med Educ, 8, 6920-8. http://dx.doi.org/10.1186/1472-6920-8-28

Gelman, A. (2005). Teaching Statistics: A Bag of Tricks. Department of Statistics and Department of Political Science, Columbia University. Retrieved from http://www.stat.columbia.edu/ gelman/ presentations/smithtalk.pdf

Ghajarzadeh, M., Abdollahzadeh, S., \& Rafiei, S. (2011). Evaluation of Knowledge and Perception of Medical Students of Tehran university of Medical Sciences about Biostatistics. Iranian Journal of Medical Education, 11(5), 455-456. Retrieved from http://ijme.mui.ac.ir/browse.php?a_code=A-10-9232\&slc_lang=fa\&sid=1

Gore, A. D., Kadam, Y. R., Chavan, P. V., \& Dhumale, G. B. (2012). Application of Biostatistics in Research by Teaching faculty and Final-year Postgraduate Students in Colleges of Modern Medicine: A cross-sectional study. Int $J$ Appl Basic Med Res, 2(1), 11-16. PMCID: PMC3657982. 
http://dx.doi.org/10.4103/2229-516X.96792

Khan, N., \& Mumtaz, Y. (2009). Attitude of Teaching Faculty towards Statistics at a Medical University in Karachi, Pakistan. Pakmedinet, 21, 166-71.

Maha, M. A., \& Tantawi, E. L. (2009). Factors Affecting Postgraduate Dental Students' Performance in a Biostatistics and Research Design Course. Journal of Dental Education, 73(5), 614-623.

Martin, M. (2003). It's Like... You Know: The Use of Analogies and Heuristics in Teaching introductory Statistical Methods. Journal of Statistics Education, 11.

Ograjenšek, I. (2005). Taking the Fear Out of Data Analysis: Case for History Lessons in Statistics Courses, International Statistical Institute, 55th Session. Retrieved from http://iase-web.org/documents/papers/ isi55/Ograjensek.pdf

Ograjenšek, I., \& Bavdaž Kveder, M. (2003). Student Acceptance of ITT-Supported Teaching and Internal Course Administration: Case of Business Statistics. In Statistics Education and the Internet, Proceedings of the IASE Satellite Conference on Statistics Education, Berlin, August 11- 12, 2003, CD-ROM. Voorburg, The Netherlands: International Statistical Institute and International, Association for Statistical Education.

Polychronopoulou, A., Eliades, T., Taoufik, K., Papadopoulos, M. A., \& Athanasiou, A. E. (2011). Knowledge of European Orthodontic Postgraduate Students on Biostatistics. Eur J Orthod, 33(4), 434-440. http://dx.doi.org/10.1093/ejo/cjq098

Sami, W. (2010). Biostatistics Education for Undergraduate Medical Students. Biomedica, 26, 80-84.

Stander, I. (1999). Teaching Conceptual vs Theoretical Statistics to Medical Students. International Statistical Institute, 52 nd Session. 1999. Retrieved Dec 29th, 2011 from http://www.stat.auckland.ac.nz/ iase/publications/5/stan0219.pdf

Strasak, A. M., Qamruz Zaman, Pfeiffer, K. P., Göbel, G., \& Ulmer, H. (2007). Statistical Errors in Medical Research - a review of common pitfalls. Swiss Med Wkly, 137, 44-49.

Swetha, J. L., Arpita, R., Srikanth, C., \& Nutalapati, R. (2014). Cognition, Comprehension and Application of Biostatistics in Research by Indian Postgraduate Students in Periodontics. J Indian Soc Periodontol, 18(1), 65-8. http://dx.doi.org/10.4103/0972-124X.128219

Wadhwa, M., Kalyan, P., \& Kalantharakath, T. (2015). Knowledge and Attitude of Medical and Dental Postgraduate Students toward Practice of Biostatistics. Journal of Postgraduate Medicine, Education and Research, 49(1), 1-4.

West, C. P., \& Ficalora, R. D. (2007). Clinicians' Attitude towards Biostatistics. Mayo clinic proceedings, 82, 939-943. http://dx.doi.org/10.4065/82.8.939

Windish. D. M., Huot, S. J., \& Green, M. L. (2007). Medicine Residents' Understanding of the Biostatistics and Results in the Medical Literature. JAMA, 5, 298(9), 1010-22.

.Windish, D. M. (2011). Brief Curriculum to Teach Residents Study Design and Biostatistics. Yale Primary Care Residency Program, USA. Evid Based Med, 16(4), 100-104. http://dx.doi.org/10.1136/ebm.2011.04.0011

Wulff, H. R., Andersen, B., Brandenhoff, P., \& Guttler, F. (1987). What do Doctors Know about Statistics?. Statist. Med, 6, 3-10. http://dx.doi.org/10.1002/sim.4780060103

\section{Copyrights}

Copyright for this article is retained by the author(s), with first publication rights granted to the journal.

This is an open-access article distributed under the terms and conditions of the Creative Commons Attribution license (http://creativecommons.org/licenses/by/3.0/). 